\title{
TRASLADO O RETENCIÓN ILÍCITOS DE MENORES TRAS LA REFORMA DE 2015: RAPIDEZ, ESPECIALIZACIÓN Y... ALGUNAS AUSENCIAS
}

\author{
Rosario Espinosa CALABUig \\ Profesora titular de Derecho internacional privado \\ Universitat de València
}

\begin{abstract}
SUMARIO: 1. ADECUACIÓN DE LA REFORMA A LA NORMATIVA EUROPEA E INTERNACIONAL SOBRE TRASLADO O RETENCIÓN ILÍCITOS DE MENORES.-2. REFORZAMIENTO DE LAS REGLAS PARA EL RÁPIDO REGRESO DEL MENOR.-3. REFORZAMIENTO DE LAS REGLAS PARA DECLARAR LA ILICITUD DEL TRASLADO DE UN MENOR AL MARGEN DE LA DECISIÓN SOBRE EL FONDO DEL ASUNTO.
\end{abstract}

\section{ADECUACIÓN DE LA REFORMA A LA NORMATIVA EUROPEA E INTERNACIONAL SOBRE TRASLADO O RETENCIÓN ILÍCITOS DE MENORES}

Basta una breve una visita a la base de datos de INCADAT ${ }^{1}$ para evidenciar una realidad: el fenómeno del traslado ilícito internacional de menores, lejos de disminuir, sigue en aumento a nivel mundial, incluida España. Esta circunstancia, unida a la nueva casuística generada en los últimos tiempos en nuestro país ${ }^{2}$, la lentitud en la tramitación de estos casos por nuestras autoridades y la anticuada y desfasada regulación que teníamos en España en esta materia -básicamente arts. 1.902 y ss. de la Ley de Enjuiciamiento Civil (LEC) de 1881-, han justificado la reacción, por fin, de nuestro legislador. Le ha costado... Pero al fin tenemos una nueva Ley 15/2015, de 2 de julio, de la jurisdicción voluntaria (LJV) que ha introducido en la LEC un nuevo Capítulo IV bis relativo a «Medidas relativas a la restitución o retorno de menores

${ }^{1}$ International Child Abduction Data Base, en http://www.incadat.com.

2 En concreto, han aumentado los casos de traslado ilícito del menor llevados a cabo por el titular del derecho de custodia, así como por causas de violencia de género, por parte del progenitor maltratado como vía de alejamiento del maltratador. Véase KAYE, M., «The Hague Convention and the flight from domestic violence: how women and children are being returned by coach and four», IJLPF, 1999, p. 191. 
en los supuestos de sustracción internacional». La DF 3. a, punto 10, de la LJV introduce en la LEC dicho capítulo con los nuevos art. 778 quáter, art. 778 quinquies y art. 778 sexties, situándose dentro de los procesos especiales matrimoniales y de menores.

La reforma moderniza así el sistema hasta ahora vigente, entre otras razones porque ha otorgado un carácter contencioso al procedimiento - ya no voluntario - para la restitución del menor trasladado o retenido ilícitamente. Este cambio ayudará presumiblemente al cumplimiento de los objetivos con que se han elaborado los preceptos citados, principalmente la rapidez en el procedimiento, a través de vías como la especialización y la concentración de la jurisdicción ${ }^{3}$ y el acortamiento de plazos tanto para la primera instancia como para la apelación. La reforma, además, no ha venido sola pues el verano del 2015 trajo consigo otras más que pueden, a su vez, tener repercusión sobre la protección del menor ${ }^{4}$.

No hay que olvidar que el objetivo principal con el que se elaboró, primero el Convenio de La Haya (CLH) de $1980^{5}$, y luego el Reglamento CE núm. $2201 / 2003^{6}$ fue el de garantizar el regreso inmediato del menor tras un traslado o retención ilícitos cometido por uno de los «titulares de la responsabilidad parental » ${ }^{7}$. Y fue dicho objetivo el que justificó la introducción de una norma - polémica y discutible- en el Reglamento núm. 2201/2003 como es la del art. 11.8 (y el art. 42 al que se remite). Dichas normas aluden a la eliminación del exequatur respecto a la decisión de regreso del menor dictada por los tribunales de un Estado miembro (EM) - aquel de residencia habitual del menor anterior a su traslado ilícito-, no obstante una previa decisión judicial dictada en otro Estado miembro que ordenaba todo lo contrario, esto es, el no regreso del menor por operar una de las causas de excepción previstas en el CLH 1980 en su art. 13. Ya no es el juez del Estado requerido el

3 Será competente el Juzgado de Primera Instancia de la capital de la provincia, de Ceuta o Melilla, con competencias en materia de Derecho de familia, en cuya circunscripción se halle el menor que haya sido objeto de un traslado o retención ilícitos, si lo hubiere y, en su defecto, al que por turno de reparto corresponda (art. 778 quáter $2 .^{\circ}$ ).

4 En particular, la reforma operada por la Ley 26/2015, de 28 de julio, de modificación del sistema de protección a la infancia y a la adolescencia. Cabe recordar también la nueva Ley 29/2015, de 30 de julio, de cooperación jurídica internacional en materia civil, así como la modificación de la LOPJ operada por la LO 7/2015, de 21 de julio.

5 Convenio sobre los aspectos civiles de la sustracción internacional de menores, hecho en La Haya el 25 de octubre de 1980 (BOE núm. 202, de 24 de agosto de 1987). Para un estado de las ratificaciones, http://www.hcch.net.

${ }^{6}$ Reglamento CE núm. 2201/2003, del Consejo, de 27 de noviembre, relativo a la competencia, el reconocimiento y la ejecución de resoluciones judiciales en materia matrimonial y de responsabilidad parental por el que se deroga el Reglamento CE núm. 1347/2000 (DO L núm. 338, de 23 de diciembre de 2003).

7 Utilizando la terminología del Reglamento núm. 2201/2003, ya que por la fecha el CLH se centraba en los casos de traslado ilícito cometidos por el titular del derecho de visita. Y en línea con el reglamento el nuevo art. 778 quáter $3 .^{\circ}$ de la LEC legitima a todos ellos para promover el procedimiento ( "persona, institución u organismo que tenga atribuida la guarda y custodia o un régimen de estancia o visitas, relación o comunicación del menor», además de la Autoridad Central, como ya estaba en el régimen anterior). 
que procede al control de la ejecutividad de la decisión, sino el juez de origen mediante la emisión de un certificado que deberá satisfacer unas condiciones concretas $^{8}$. La publicación el 30 de junio de 2016 (al cierre de las pruebas de imprenta de este trabajo) de la Propuesta de un nuevo Reglamento que aspira a «refundir» el actual Reglamento núm. 2201/2003, anuncia una modificación de las reglas en materia de sustracción de menores que será, sin duda, bienvenida.

La reforma de la LEC operada a través de la LJV se convierte en el complemento indispensable de la regulación existente en el marco de la Unión Europea y del CLH 1980, de ahí que aluda a ella en el primer párrafo del art. 778 quáter y de ahí que la DF 22. ${ }^{a}$ de la LEC contenga las medidas para facilitar la aplicación en España del Reglamento núm. 2201/2003 en lo atinente, entre otros extremos, al aún vigente art. 11 (puntos 6 y 7 de dicha disposición final de la LEC, según la nueva redacción dada por la DF 3. a de la LJV núm. 19).

\section{REFORZAMIENTO DE LAS REGLAS PARA EL RÁPIDO REGRESO DEL MENOR}

No obstante el carácter discutible de las normas citadas del actual Reglamento núm. $2201 / 2003^{9}$, pues ponen en conflicto dos decisiones divergentes de los tribunales de dos Estados miembros y refuerzan al juez de origen ${ }^{10}$, el legislador español ha llevado a cabo una reforma que favorecerá su cumplimiento en los casos de traslado ilícito dentro de la UE (habrá que ver, en todo caso, cómo quedan estas normas en el nuevo Reglamento, sin olvidar las críticas y dudas manifestadas en relación con la normativa actualmente vigente a través de alguna jurisprudencia, en particular del Tribunal Europeo de Derechos Humanos - TEDH - en Sentencias como la de 18 de junio de 2013, en el asunto Sofia Povse ${ }^{11}$. La introducción en la LEC del nuevo Capítulo IV pretende, al igual que el art. 11.8 (y el art. 42) del Reglamento núm. 2201/2003 y las normas del CLH 1980 (art. 1), potenciar el regreso lo más

\footnotetext{
8 Sobre los recelos y críticas hacia el art. 11.8 del Reglamento núm. 2201/2003, véase EsPINOSA Calabuig, R., «La sottrazione di minori nell'Unione Europea: tra Regolamento n. 2201/2003 e Convenzione dell'Aja del 1980», en CARbone, S. y QuEIRolo, I. (dirs.), Diritto di famiglia e Unione Europea, Turín, Chiappichelli., 2008, pp. 283-314.

9 La jurisprudencia del Tribunal de Justicia de la Unión Europea (TJUE) sobre el Reglamento núm. 2201/2003, incluyendo el art. 11.8, es ya abundante. Por ejemplo, Sentencias como las de 11 de julio de 2008, as. C-195/08 PPU; de 16 de julio de 2009, as. C-168/08; de 23 de diciembre de 2009, as. C-403/09; de 1 de julio de 2010, as. C-211/10 PPU; de 15 de julio de 2010, as. C-256/09; de 5 de octubre de 2010, as. C-400/10 PPU; de 9 de noviembre de 2010, as. C-296/10 PPU; de 22 de diciembre de 2010, as. C-491/10; de 22 de diciembre de 2010, as. C-497/10 PPU; de 9 de enero de 2015, as. C-498/14; o de 10 de noviembre de 2015 , as. C-455/15.

${ }^{10}$ Hasta el punto de que una vez emitido el certificado en cuestión, ya no es posible impugnar el reconocimiento en el Estado requerido de la decisión de retorno del menor, ni tampoco recurrir la expedición del certificado, siendo el Derecho del Estado de origen el que regulará cualquier posible rectificación (art. 43.1 y 2, en relación con los arts. 41.1 y 42.1).

11 Asunto Sofia Povse and Doris Povse v. Austria, núm. 3890/11, TEDH 2013. Con anterioridad el TJUE se había pronunciado con la Sentencia de 1 de julio de 2010, as. C-211/10 PPU.
} 
rápido posible del menor en los casos en que ha sido trasladado ilícitamente a nuestro país desde otro Estado (miembro de la UE o del CLH 1980) en el que el menor tenía su residencia habitual antes de su traslado ilícito a España (art. 778 quáter y art. 778 quinquies LEC, que aluden al «lugar de procedencia» y no a su residencia habitual). Pero también en los casos en que estando el menor residiendo en España ha sido trasladado ilícitamente a otro Estado (art. 778 sexties).

Todas estas normas aspiran, en definitiva, a potenciar el regreso inmediato del menor que, en último término, suponga la satisfacción del interés superior de este, con el cumplimiento de las máximas garantías y en defensa de sus derechos más fundamentales, en línea con la Convención Europea de Derechos Humanos de 4 de noviembre de $1950^{12}$. Dichas garantías se ven reforzadas en la reforma de la LEC al permitir que «a lo largo de todo el proceso» el juez pueda otorgar, de oficio, a instancia de parte o del Ministerio Fiscal «las medidas cautelares oportunas y de aseguramiento del menor que estime pertinentes conforme al art. 773, además de las previstas en el art. 158 del Código Civil». Este reforzamiento incide asimismo en la satisfacción de las reglas del Reglamento núm. 2201/2003, en relación con la «actuación urgente» del órgano jurisdiccional ante el que se interponga la demanda, que utilizará «los procedimientos más expeditivos que prevea la legislación nacional» (art. 11.3) y que no podrán denegar la restitución de un menor, basándose en el art. 13.b) del CLH 1980, si se demuestra que se han adoptado «medidas adecuadas» para garantizar la protección del menor tras su restitución (art. 11.4). Además, los «pormenores de dichas medidas» dictadas «para garantizar la protección del menor tras su restitución al Estado de su residencia habitual» (en cumplimiento del art. 11.8) deberán constar, en su caso, en el certificado al que alude el art. 42.2.c) emitido por el juez de origen.

Desde la primera lectura del nuevo Capítulo IV de la LEC se aprecia la casi obsesión (justificada por otra parte) del legislador español por la rapidez del procedimiento como única vía de garantizar el regreso inmediato del menor y, por ende, la protección de sus derechos. El art. 778 quáter $5 .^{\circ}$, deja claro que el procedimiento tendrá carácter «urgente y preferente». Deberá realizarse, «en ambas instancias», si las hubiere, en el «inexcusable plazo total de seis semanas» desde la fecha de la presentación de la solicitud instando la restitución o el retorno del menor, salvo que existan circunstancias excepcionales que lo hagan imposible. Por tanto, se acortan plazos para la primera instancia y para la apelación, fase en la que la brevedad de actuaciones será fundamental ${ }^{13}$. De igual modo el art. 778 quinquies $2 .^{\circ}$, fija el plazo de veinticuatro horas para la admisión de la demanda por el secretario judicial, y si no fuera admisible, se dará cuenta al juez para que resuelva lo que proceda dentro de

\footnotetext{
12 BOE núm. 243, de 10 de octubre de $1979 .$.

13 Según el art. 778 quinquies $11^{\circ}$, contra la resolución que se dicte solo cabrá recurso de apelación con efectos suspensivos, que tendrá tramitación «preferente», debiendo ser resuelto en el «improrrogable plazo de veinte días», señalando en los apartados $a$ )-e) los plazos para proceder con la máxima celeridad.
} 
dicho plazo. Pero además en la misma resolución en la que sea admitida la demanda, se requerirá al demandado - sustractor del menor - para que, en la fecha que se determine, que no podrá exceder de los tres días siguientes, comparezca con el menor y manifieste si accede a su restitución o retorno, o se opone a ello, alegando alguna de las causas establecidas en el CLH 1980.

Lo primero que llama la atención de estas normas es el plazo de las seis semanas para que se lleve a cabo el procedimiento, a contar desde el momento en que se presenta la solicitud de regreso del menor. De este modo, se sitúa en la línea del art. 11 del CLH $^{14}$ y del art. 11.3.2 del Reglamento núm. 2201/2003 ${ }^{15}$, en cuyo ámbito se han demostrado - hasta ahora- las dificultades prácticas para cumplir con dicho plazo, salvo algunas excepciones ${ }^{16}$. Dichas dificultades han sido consideradas en el nuevo Reglamento propuesto en 2016. El cumplimiento de un plazo lo más breve posible solo será factible en un marco de cooperación interestatal (de ahí el apoyo que el art. 778 quáter $7 .^{\circ}$, hace a las comunicaciones directas, se entiende sin intermediación alguna, al igual que la Ley de cooperación jurídica internacional) ${ }^{17}$, entre órganos jurisdiccionales de distintos países, a través del auxilio de las Autoridades Centrales implicadas, de las Redes de Cooperación Judicial Internacional existentes, de los miembros de la Red Internacional de Jueces de la Conferencia de La Haya y de los jueces de enlace, y se verá favorecido — presumiblemente- por la antes aludida concentración de las competencias y su especialización, igualmente enfatizadas por la propuesta de Reglamento de 30 de junio de 2016. Solo así, además, se podrá reducir el riesgo de manipulaciones en el cómputo de los plazos en casos en los que, por ejemplo, un traslado que ha empezado siendo lícito se ha convertido en ilícito de modo que al interponer la demanda de restitución del menor este se encuentra ya integrado en su nuevo ambiente (en línea con el art. 12 CLH 1980) ${ }^{18}$.

De hecho la clave del éxito de los arts. 11.8 y 42 del Reglamento núm. 2201/2003, tal como se regulan en la actualidad, está sin duda en la rapidez con que se tramiten los varios procedimientos en que se podrán ver envueltas las autoridades españolas: a) el llevado a cabo tras un traslado ilícito del niño a nuestro país, en cuyo caso deberán ordenar el regreso inme-

\footnotetext{
14 Referido al «plazo de seis semanas a partir de la fecha de iniciación de los procedimientos» para llegar a una decisión.

15 Según el cual el órgano jurisdiccional dictará su resolución «como máximo seis semanas después de la interposición de la demanda», salvo que existan circunstancias excepcionales que lo hagan imposible.

${ }^{16}$ A este respecto Forcada Miranda, J., «El nuevo proceso español de restitución o retorno de menores en los supuestos de sustracción internacional: la decidida apuesta por la celeridad y la novedosa Circular de la Fiscalía 6/2015 (Parte I)», pp. 36-38 (www.milleniumdipr.com), alude a países como el Reino Unido (Inglaterra y Gales), Holanda, Uruguay o Japón como ejemplos en los que la reforma legislativa en esta materia ha demostrado que la brevedad de estos plazos es posible.

17 En este ámbito, véase RodRíguez BENOT, A., «La Ley de cooperación jurídica internacional en materia civil», $C D T$ (marzo 2016), vol. 8, núm. 1, p. 239.

18 Paradigmáticas en su momento sentencias como las de la AP de Sevilla de 16 de septiembre de 2004 o AP de Madrid de 3 de marzo de 2005. Y especialmente llamativa a este respecto es la reciente STC 16/2016, de 1 de febrero.
} 
diato de este en los plazos de los arts. 778 quáter y 778 quinquies de la LEC, salvo que se demuestre alguna de las excepciones del CLH 1980. De ser así, $\mathrm{y}$ aunque nuestras autoridades consideren que el menor no debe regresar al Estado miembro en el que residía antes de su traslado ilícito, deberán $b$ ) tramitar su regreso inmediato cuando así lo hayan decidido las autoridades de dicho Estado miembro. Y ello porque esa decisión - final y definitiva- de regreso es ejecutiva sin exequatur «con el fin de garantizar la restitución del menor», según el art. 11.8 in fine en relación con el art. 42 del Reglamento núm. 2201/2003. Pasará lo mismo en los casos en que $c$ ) España sea el Estado donde el menor residía antes de su traslado y nuestras autoridades lo califiquen como ilícito (según se regula en el art. 778 sexties de la LEC) y ordenen su regreso inmediato a nuestro país, aunque en otro Estado miembro se haya decidido su no regreso por operar las excepciones del CLH 1980 (decisión, por tanto, provisional, que será superada por la definitiva dictada en España).

Los cauces procesales para llevar a cabo todas estas hipótesis no se regulan en la medida que hubiera sido deseable en los nuevos preceptos de la LEC, aunque cabe presuponer que las «medidas» a las que se alude en ellos se utilizarán en todo caso. En particular el art. 778 quinquies $13 .^{\circ}$ señala que la ejecución de la sentencia en la que se acuerde la restitución del menor o su retorno al Estado de procedencia (incluso habiendo oposición del progenitor sustractor), se realizará «de forma inmediata». Para ello, el juez deberá adoptar las medidas necesarias y podrá ayudarse de la asistencia de los servicios sociales y de las Fuerzas y Cuerpos de Seguridad. Para hacer efectiva dicha actuación, la Autoridad Central prestará la necesaria asistencia al Juzgado para garantizar que se realice sin peligro, adoptando las medidas administrativas precisas. (art. 778 quinquies $13 .^{\circ}$ ). Debe entenderse que todas estas medidas se adoptarán siempre que haya que tramitar un regreso rápido del menor desde nuestro país, tanto cuando está aquí retenido ilícitamente, como cuando lo está en otro Estado miembro y las autoridades españolas ordenan su regreso a España (en cuanto Estado miembro de residencia habitual del menor antes de su traslado ilícito). En cambio, cuando el menor deba regresar a nuestro país desde otro Estado miembro en el que el menor está retenido ilícitamente, el regreso se llevará con arreglo a las medidas fijadas por su normativa interna, de ahí la importancia de la cooperación interestatal para que, en todo caso, el regreso del menor se lleve con éxito y con salvaguarda de su interés.

A pesar de las contradicciones que provoca el art. 11.8 del Reglamento núm. 2201/2003 este ha recibido el respaldo del TJUE sin siquiera dar opción a excepciones, lo que ha provocado un claro conflicto interpretativo en torno a la protección de los derechos fundamentales y la misma concepción del interés del menor en este tipo de casos, como se demostró en los mencionados asuntos Aguirre Zárraga y Sofia Povse. La insistencia en defender la aplicación del art. 11.8 no parece coherente con la defensa de lo que pueda constituir el interés superior del menor, en cada caso en particular, aunque se haya cometido un acto que, en principio, va a ser calificado como ilícito 
en los términos del Reglamento núm. 2201/2003 y del CLH 1980. La reforma que se realice del art. 11.8 del Reglamento deberá tener en cuenta el difícil equilibrio entre la valoración del interés del menor en cada caso, y el riesgo de interpretaciones que puedan favorecer excepciones a la norma con las manipulaciones como las que, hasta ahora, se han realizado en el ámbito del CLH 1980. No será fácil.

Mientras tanto, la celeridad en el procedimiento seguirá poniendo de manifiesto las dificultades interpretativas en cuestiones tan relevantes como, por ejemplo, la audiencia del menor, a la que el art. 778 quinquies $8 .^{\circ}$, de la LEC le otorga un papel fundamental. Ello deriva, entre otras razones, de las diferentes concepciones que recibe en los Estados (dentro de la UE, por ejemplo, hay países como Alemania donde aparece configurado como un principio de rango constitucional y en otros, en cambio, ha sido prácticamente inexistente durante años $)^{19}$. Dicho riesgo era previsible desde que se elaboró el Reglamento núm. 2201/2003 en relación con el requisito del certificado del art. 42 relativo a la audiencia del menor. El asunto Aguirre Zárraga es buena muestra de este conflicto ${ }^{20}$, como también la respuesta del TEDH en el mencionado asunto Sofia Povse 21 .

Fuera de la UE, en el ámbito del CLH 1980, los nuevos preceptos de la LEC garantizarán el mismo objetivo de inmediatez en el regreso del menor, aunque sin los conflictos derivados de la eliminación del exequatur previsto por el Reglamento núm. 2201/2003. No olvidemos que el CLH 1980 privilegia el pronto regreso del menor, independientemente del reconocimiento de la decisión judicial. En cambio, el Convenio de Luxemburgo de $1980^{22}$ (con el que el CLH 1980 ha demostrado sus problemas de complementariedad) se centra en el exequatur, subordinando el regreso del menor trasladado ilícitamente al reconocimiento y ejecución de la decisión judicial en el Estado interesado. Ambos se han ratificado por los países de la UE en épocas diferentes y a menudo distantes la una de la otra, lo que ha provocado alguna que otra diferencia interpretativa. Pero todos los Estados concuerdan en los problemas prácticos que los dos Convenios han provocado, sobre todo el carácter

19 Véase VölKer, M., «Le règlement "Bruxelles II bis” du point de vue d'un juge aux affaires familiares allemand», en Fulchiron, H. y Nourissat, C. (dirs.), Le nouveau droit communitaire du divorce et de la responsabilité parentale, París, Dalloz, pp. 293-302.

20 STJUE de 22 de diciembre de 2010, as. C-491/10 PPU. A juicio del TJUE el órgano competente del Estado miembro de ejecución no puede oponerse a la ejecución de una resolución certificada que ordena la restitución del menor ilícitamente retenido, por considerar que el órgano del Estado miembro de origen, del que emana esta resolución, ha vulnerado el art. 42 del Reglamento, interpretado conforme al art. 24 de la Carta de los Derechos fundamentales de la UE, por cuanto la apreciación de la existencia de tal vulneración compete exclusivamente a los órganos jurisdiccionales del Estado miembro de origen.

${ }^{21}$ Véase comentario de KINSch, P., al hilo de «Harroudj v. France: indications from the European Court of Human Rights on the nature of choice of law rules and on their potentially discriminatory effect», YPIL, 2013/2014, vol. 15, pp. 39-44.

${ }^{22}$ Convenio Europeo sobre reconocimiento y ejecución de resoluciones en materia de custodia de menores y restablecimiento de esa custodia de 20 de mayo de 1980 (BOE núm. 210, de 1 de septiembre de 1984). Para un estado de las ratificaciones http://www.conventions.coe.int. 
lento y farragoso del procedimiento, que ha obstaculizado notablemente la efectividad de los mismos ${ }^{23}$.

La celeridad en el procedimiento permitirá, por otra parte, frenar el riesgo de un uso manipulado del art. $12 \mathrm{CLH}$ al que nos hemos referido antes ya que, aunque no regula las causas de excepción al regreso del niño tras su traslado ilícito (para ello está el art. 13), en la práctica se ha utilizado como tal al permitir que, transcurrido un año desde su traslado o retención ilícita, el niño no tuviera que regresar al demostrarse su integración «en su nuevo ambiente». Las dificultades prácticas de localización del menor en muchos casos pueden seguir favoreciendo ese riesgo, de ahí que deba interpretarse como un año desde que se conozca el paradero del menor. De hecho, el art. 778 quinquies $3 .^{\circ}$, señala que si el menor no fuera localizado «se archivará provisionalmente el procedimiento hasta ser encontrado». La duración de dicha provisionalidad se ignora, pero se sabe que un año pasa rápidamente y que en ese plazo el niño puede perfectamente integrarse en su nuevo ambiente... En este sentido, el art. 778 quinquies $5 .^{\circ}$, alude a los casos en que el demandado - sustractor- no compareciese ni procediera a la entrega del menor, en cuyo caso se le declarará en rebeldía pero el procedimiento seguirá su curso, citando únicamente al demandante y al Ministerio Fiscal a una vista ante el juez que tendrá lugar «en un plazo no superior a los cinco días siguientes», a celebrar según lo dispuesto en el precepto. Dicha resolución, no obstante, deberá ser notificada al demandado, tras lo cual no se llevará a cabo ninguna otra, excepto la de la resolución que ponga fin al proceso.

En los casos en que el demandado sí que comparezca, pero para invocar las causas de excepción al regreso del menor (las del art. 13 CLH 1980), el secretario judicial «en el mismo día» dará traslado de la oposición y citará a todos los interesados y al Ministerio Fiscal a una vista que se celebrará «dentro del improrrogable plazo de los cinco días siguientes». La vista no se suspenderá, por otra parte, por incomparecencia del demandante o del demandado (art. 778 quinquies $6 .^{\circ}$ y $7 .^{\circ}$ ), lo que no solo es una novedad sino que refuerza la rapidez del procedimiento.

La rapidez en el procedimiento se pone de manifiesto incluso en los casos en que se consiga someter el caso a mediación entre las partes (a instancia de las partes o por el juez), «sin que ello deba suponer un retraso injustificado del proceso» y con un procedimiento que será «lo más breve posible» (art. 778 quinquies $12 .^{\circ}$ ).

Por último, hay que incidir en la relevancia de la celeridad en relación con una cuestión fundamental para el éxito de todas estas normas (LEC, Reglamento y Convenio), como es la presentación de las pruebas dirigidas a excepcionar el regreso del menor trasladado o retenido ilícitamente, con base en las causas reguladas en el CLH 1980. No obstante su relevancia, ninguno de

23 Espinosa Calabuig, R., op. cit., nota 8, pp. 284-285. 
los textos mencionados lo regula con exhaustividad, aunque el art. 778 quinquies le atribuye mucha trascendencia. En particular, el art. 778 quinquies $7 .^{\circ}$ in fine, se refiere a las pruebas presentadas al proceso, a instancia de parte, del juez o del Ministerio Fiscal (antes solo podían presentarse a instancia de parte), que sean relevantes para la decisión sobre la ilicitud o no del traslado o retención y las medidas a adoptar, que lo harán «dentro del plazo improrrogable de seis días», así como los informes que estime pertinentes cuya realización será «urgente y preferente» a cualquier otro proceso.

La relevancia que dicho precepto otorga a la presentación de pruebas e informes en el sentido expuesto en el párr. 7, incide no solo sobre las garantías hacia el menor sino también sobre el cumplimiento, una vez más, del actual art. 11.8 del Reglamento núm. 2201/2003, en particular sobre el art. 42 al que se remite. En el apartado 2.c) de este último se regula el tercero de los requisitos que debe cumplir el certificado que emitirá el juez de origen de la resolución que ordena el regreso definitivo del menor (para que pueda ser ejecutiva sin exequatur). Esto es, la comprobación por dicho juez [junto a la audiencia del menor y de las partes de los apdos. a) y b)] de que la decisión de no retorno del menor fue ordenada por el juez de otro Estado miembro, teniendo en cuenta, al dictar su resolución, «las razones y las pruebas» en las que esta se fundamenta en virtud del art. 13 CLH 1980.

Todas esas «razones y pruebas» son las mismas a las que el art. 778 quinquies da preponderancia, con el alcance descrito, para justificar la decisión de las autoridades españolas en favor del regreso o no del menor en casos de traslado ilícito. Pero, además, esas mismas «razones y pruebas» son las que deberá valorar el juez de origen de una decisión de regreso del menor, en el marco del certificado del art. 42 del Reglamento núm. 2201/2003, no obstante la de no regreso que haya sido dictada en España. Mientras no se reforme dicha norma, los conflictos interpretativos al hilo de tales «razones y pruebas» seguirán en aumento.

\section{REFORZAMIENTO DE LAS REGLAS PARA DECLARAR LA ILICITUD DEL TRASLADO DE UN MENOR AL MARGEN DE LA DECISIÓN SOBRE EL FONDO DEL ASUNTO}

A la luz del nuevo art. 778 sexties, parece que el legislador ha querido reforzar otros dos objetivos claves en esta materia. De un lado, la declaración del traslado o retención de un menor como ilícito, para lo que se aportan reglas sobre la necesidad de obtener una certificación (conforme al CLH o al Reglamento) en dicho sentido. De otro, la aclaración sobre la tradicional confusión entre la decisión de regreso inmediato del menor y la decisión sobre el fondo del litigio. Aspectos que, como es sabido, han sido muchas veces confundidos en la jurisprudencia — no solo española- y aprovechados por el sustractor del menor para, a través de manipulaciones procesales, obtener una nueva decisión sobre el fondo. Con el nuevo precepto se aspira a aclarar dicha cuestión, a pesar de las persistentes dificultades que la práctica arro- 
$\mathrm{ja}^{24}$, y las disparidades interpretativas respecto a lo que se considera o no como una infracción del derecho de custodia (necesario, entre otros, para definir el traslado o retención del menor como ilícitos, en los términos fijados por el art. 3 CLH 1980 o el art. 1.11 del Reglamento núm. 2201/2003)25. Es por ello que el nuevo precepto de la LEC se muestra insuficiente, además de vago, para cumplir con el segundo de los objetivos expuestos.

Como ya se ha señalado, tanto el CLH 1980 como el Reglamento núm. 2201/2003 aspiran a favorecer el regreso inmediato del niño, dejando para un momento posterior, que no se regula como debiera en ninguno de los dos textos, la decisión sobre los derechos de custodia ${ }^{26}$. Tampoco la nueva regulación de la LEC aporta luz al respecto. Conforme al CLH la autoridad - judicial o administrativa- del Estado al que el niño ha sido trasladado ilícitamente no puede decidir sobre el fondo hasta que se haya determinado que no se reúnen las condiciones del Convenio para la restitución ${ }^{27}$ y en similares términos, pero más confusos si cabe, se expresa el Reglamento núm. 2201/2003 en su art. 11.7. De la comprensión de ambas cuestiones y su trato diferenciado depende no solo el buen funcionamiento de todos estos textos, sino también el fin de las manipulaciones procesales aludidas.

A este respecto, la jurisprudencia del TJUE ha interpretado que el art. 11.8 del Reglamento no se opone, en principio, a que un Estado miembro atribuya a un tribunal especializado la competencia para examinar las cuestiones de restitución o de custodia del menor en el marco del procedimiento previsto, incluso cuando un órgano jurisdiccional ya conozca por otra parte de un procedimiento sobre el fondo acerca de la responsabilidad parental en relación con el menor ${ }^{28}$. Es más, el art. 11.8 debe interpretarse en el sentido de que «una resolución del órgano jurisdiccional competente que ordena la restitución del menor está comprendida en el ámbito de aplicación de dicha disposición, aun cuando no esté precedida de una resolución definitiva del mismo órgano jurisdiccional relativa al derecho de custodia del menor ${ }^{29}$, puesto que dicha resolución solo podrá dictarse posteriormente a la de la restitución, en su caso, del menor ${ }^{30}$.

${ }^{24} \mathrm{El}$ asunto Aguirre Zárraga es una buena muestra, puesto que a pesar de la decisión de regreso del menor —ejecutiva sin exequatur - ordenada por el juzgador español, el alemán entra a resolver el fondo del asunto. STJUE de 22 de diciembre de 2010, as. C-491/10 PPU, con comentario de ÁLVAREZ GonZaLEZ, S., en REDI, vol. LXII (2010), 2, p. 249.

25 Por ejemplo, la SAP de Málaga de 1 de abril de 2014, respecto a las disparidades entre la legislación lituana y la española en dicho punto.

26 El art. 19 CLH 1980 establece que la decisión sobre el retorno del niño no se tendrá en cuenta para determinar el fondo respecto a su custodia.

$27 \mathrm{O}$ bien haya transcurrido un periodo de tiempo razonable sin que se haya presentado una solicitud en virtud del Convenio (art. 16).

28 STJUE de 9 de enero de 2015, as. C-498/14, D. Bradbrooke c. A. Aleksandrowicz.

29 STJUE de 1 de julio de 2010, as. C-211/10 PPU, Sofia Povse and Doris Povse c. Austria.

30 Con ocasión del asunto Bianca Purrucker y Guillermo Vallés Pérez, la STJUE de 9 de noviembre de 2010, as. C-296/10 PPU, estableció que en el marco de un procedimiento de medidas provisionales, el hecho de que se incoe ante un órgano jurisdiccional de un Estado miembro un procedimiento de 
En este sentido, el art. 778 sexties señala que cuando sea España el país en el que el menor residía antes de su traslado ilícito a otro país, cualquier persona interesada, «al margen del proceso que se inicie para pedir su restitución internacional», podrá dirigirse en España a la autoridad judicial competente para conocer del fondo del asunto con la finalidad de obtener una resolución que especifique que el traslado o la retención han sido ilícitos, a cuyo efecto podrán utilizarse los cauces procesales disponibles en el Título I del Libro IV para la adopción de medidas definitivas o provisionales en España, e incluso las medidas del art. 158. Se echa en falta, en definitiva, una mayor precisión en una cuestión de tanta relevancia práctica.

Palabras clave: sustracción internacional de menores, Reglamento 2201/2003, Convenio de La Haya 1980, Ley Jurisdicción Voluntaria.

Keywords: international child abduction, Regulation 2201/2003, Hague Convention 1980, Voluntary Jurisdiction Act.

este tipo y no se desprenda que este es competente en el sentido del Reglamento núm. 2201/2003, «no excluye necesariamente que exista, según lo permita eventualmente el Derecho nacional de ese Estado miembro, una demanda sobre el fondo vinculada a la demanda de medidas provisionales [...]». 